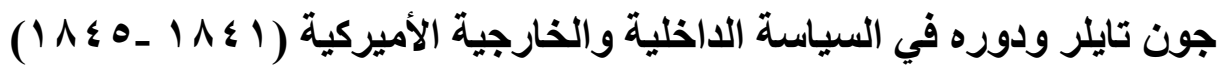

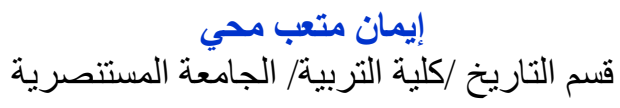

emanaltemimy@gmail.com

Received: August 25, 2019 Accepted: June 28, 2020 Online Published: September 29, 2020

DOI: http://doi.org/10.36231/coeduw/vol31no3.8

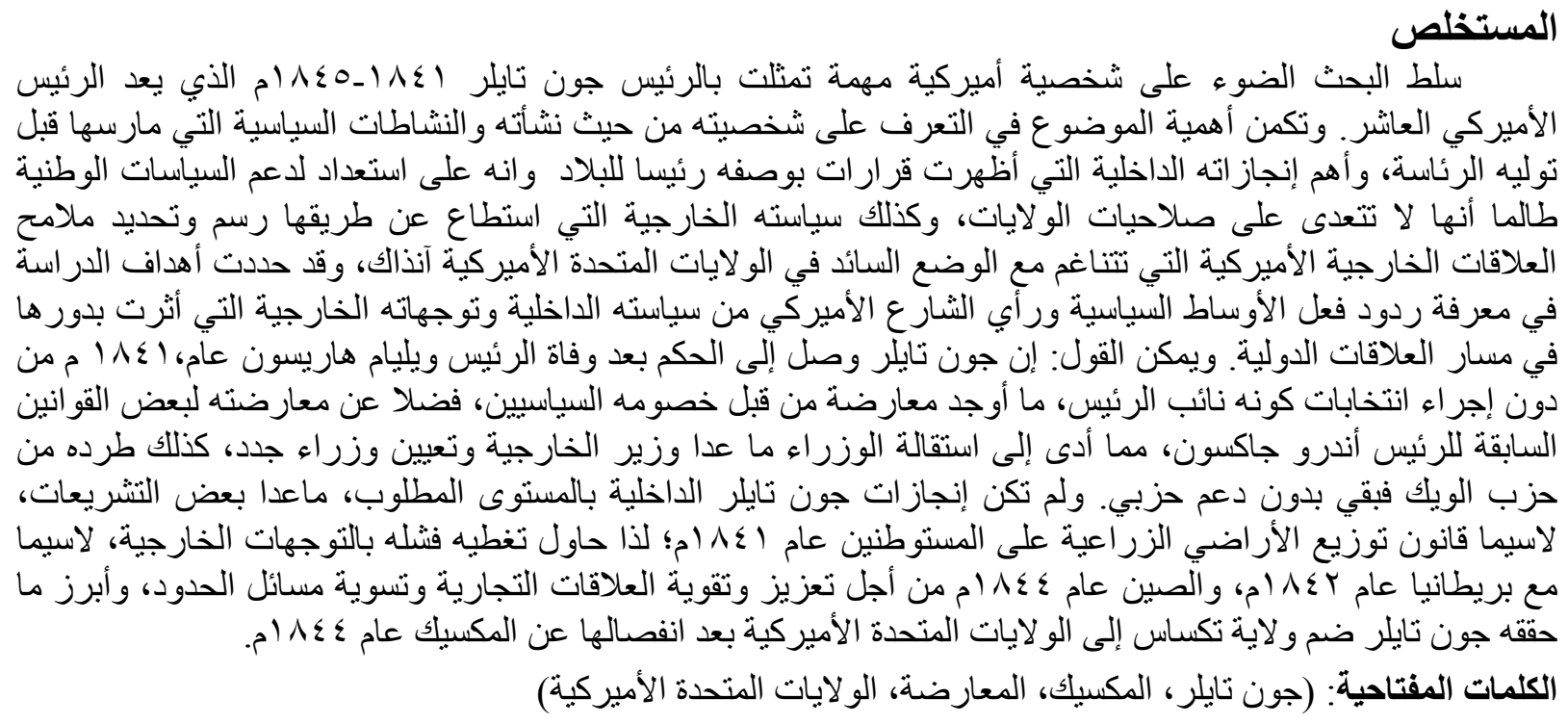

\title{
John Tyler and his Role in the America Domestic and Foreign Policy (1841- 1845)
}

\author{
Eman Mutaib Muhe \\ Department of History/College of Education/ \\ Mustansirya University \\ emanaltemimy@gmail.com
}

\begin{abstract}
The current paper highlights an important character represented by the American president John Tyler 1841 - 1845, who is considered the tenth American president. The importance of this paper lies in identifying his personality in terms of his upbringing and the political activities he practiced before assuming the presidency and his most significant internal achievements, which showed his decisions as a president. He was fully prepared to support national policies since they do not exceed the authorities of the states. With his achievements in the foreign policy, he was capable to draw and define the features of the American foreign relations that were in harmony with the general situation in the United States of America at that time. John Tyler came to power after the death of President Henry William Harrison in 1841, without elections. Being vice-President resulted an opposition from his political opponents, as well as his opposition to some of the previous laws of president Andrew Jackson, which consequently led to the resignation of whole Ministers (except the Minister of Foreign affairs), however, he has appointed new Ministers. After that he had been expelled from Whig Party, so
\end{abstract}


he remained without any partisan support, because John Tylers' achievements were not at the required level, except for some legislation issues, that including the agricultural distribution law of the land for the settlers in 1841, then as trying to cover his failure within external directions especially with Britain in 1842 and China in 1844, in order to strengthen trade relations and resolve border issues, John Tyler had achieved some matters by joining Texas to the United States, after its secession from Mexico in 1844.

\section{Keywords: Jhon Tyler, Mexico, Opposition, United States}

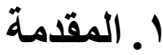

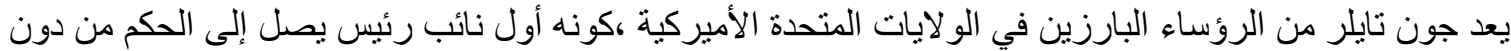

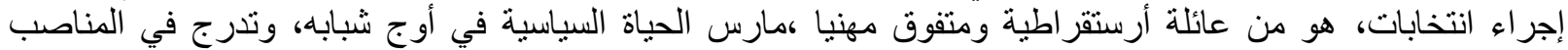

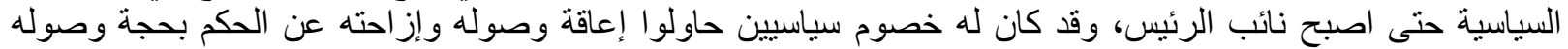

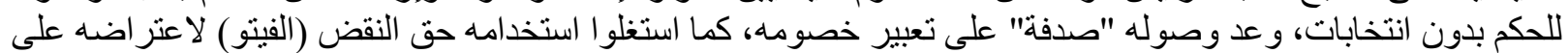

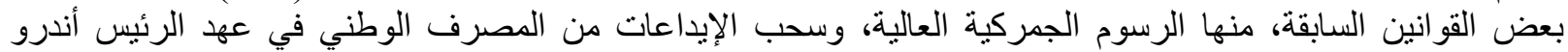

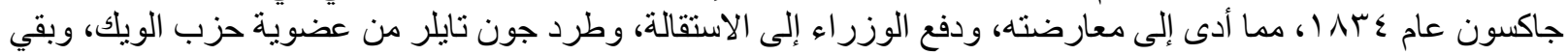

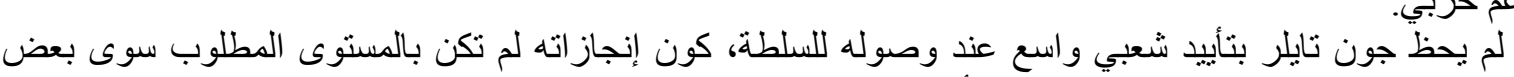

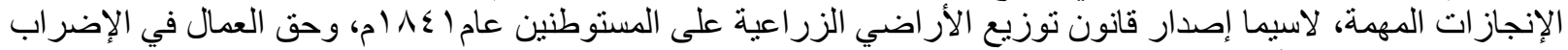

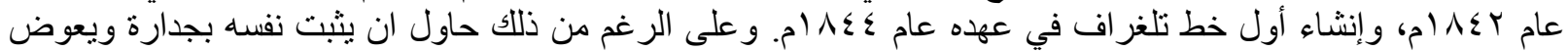

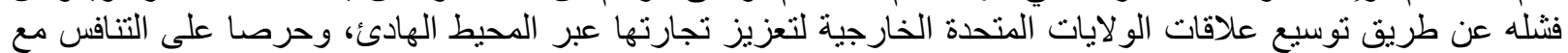

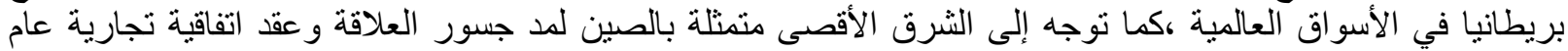

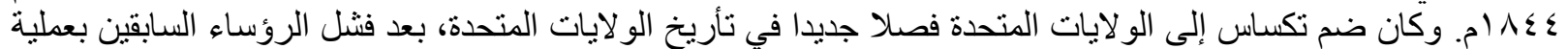

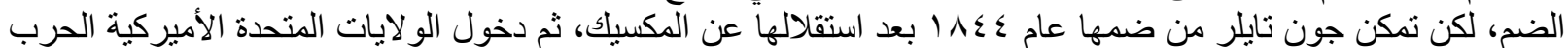

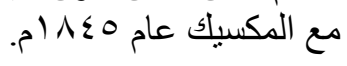

\section{اولا: المبحث الأول

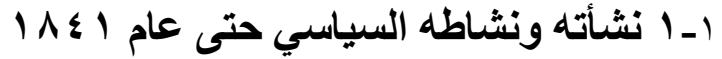

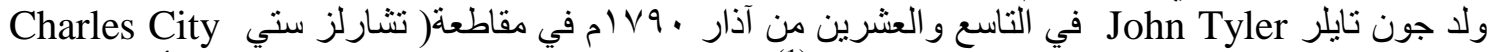
(Monroe, 2003, p. 110) توفيت و الدته (ماري ارمستيد Mary Armistead حينما كان عمره سبع سنوات (Tyler,1970, p. 300) تاركة تربيته

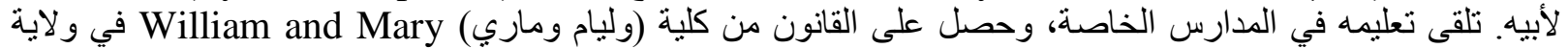

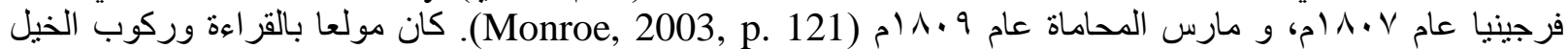

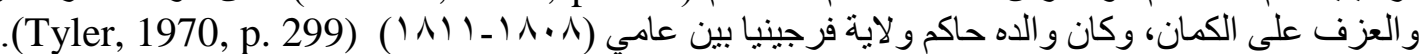

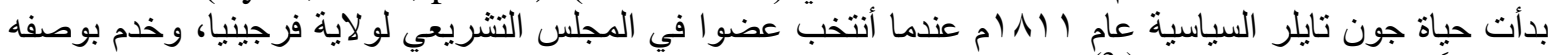

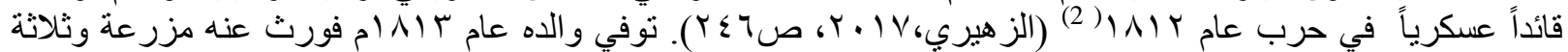

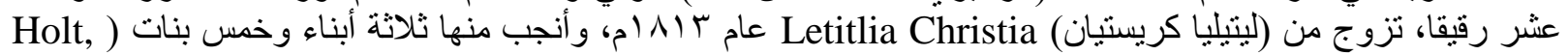
.(1992, p. 88

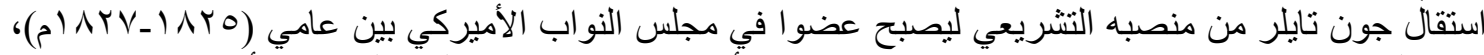

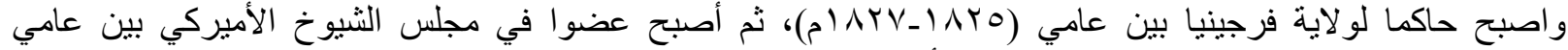

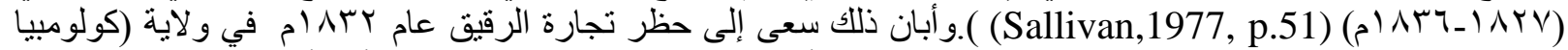
(Colombia

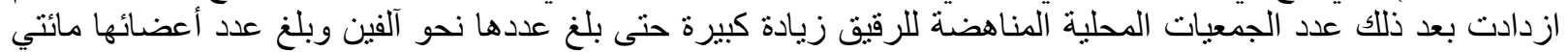

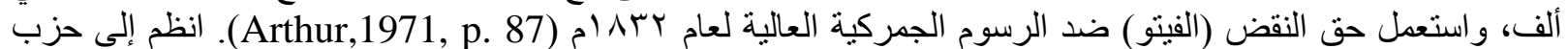

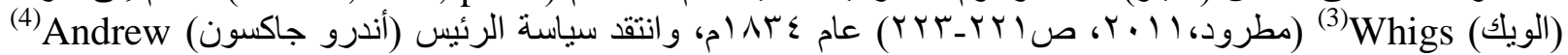

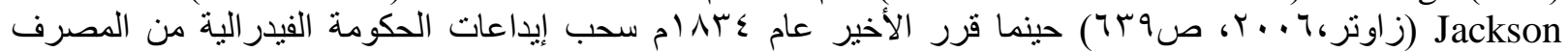

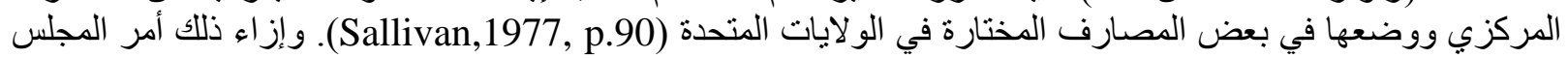

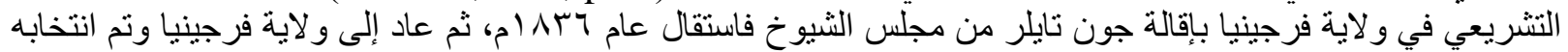

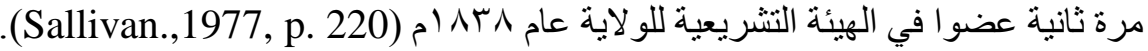


حقق جون تايلر على نحو سريع شهرة كونه حازما وحاسما في اتخاذ القرارات؛ و هذا بعني بأنه من مؤيدي المبدأ

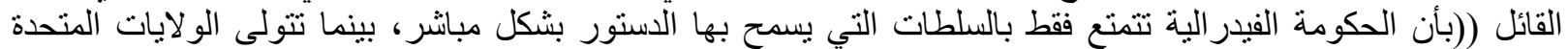

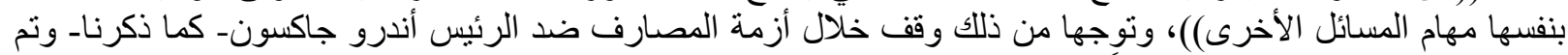

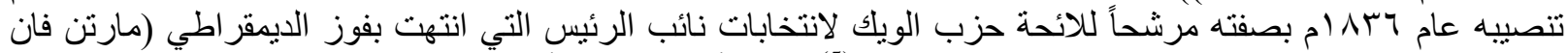

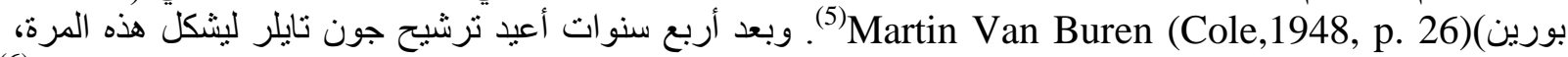

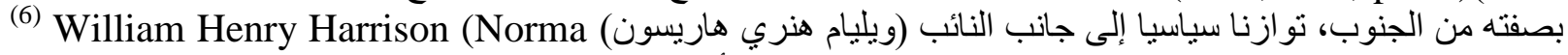
(Peterson,1989, p. 68)

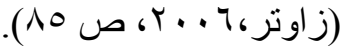

\section{ثانيا: المبحث الثناني \\ r - أبا: المبحم جون تائي الحكم وسياسته الداخلية}

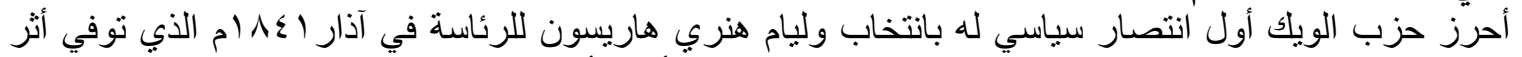

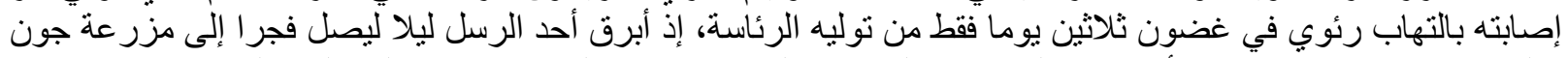

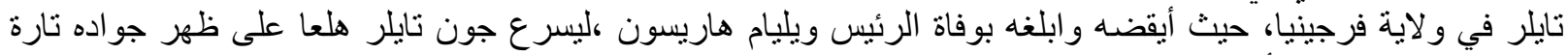

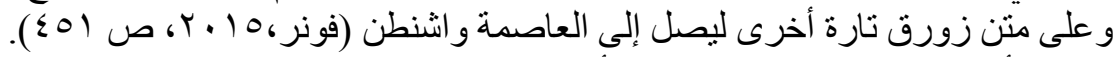

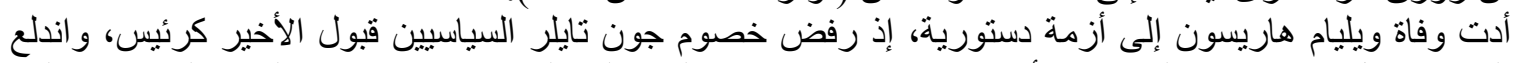

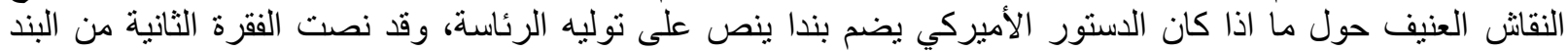

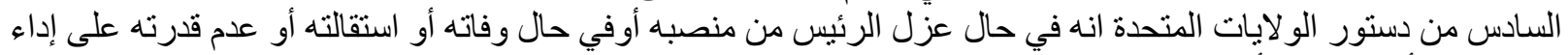

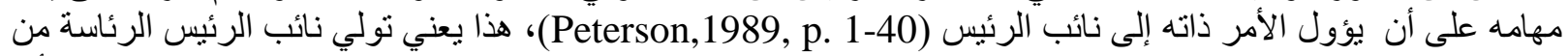

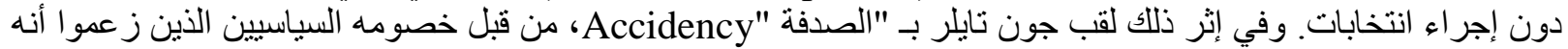

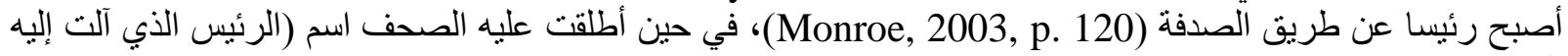

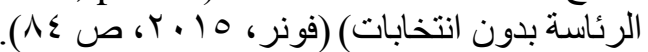

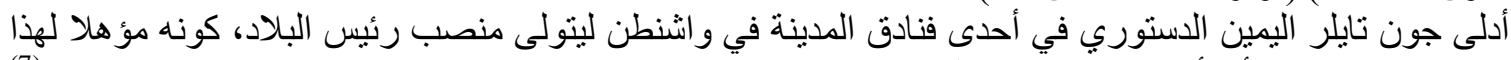

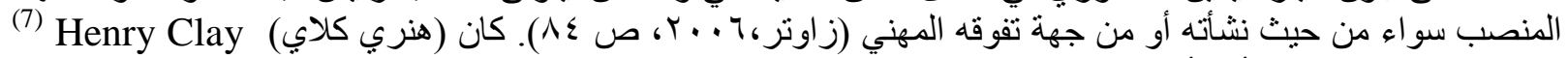
(Eaton,1957, p.98)

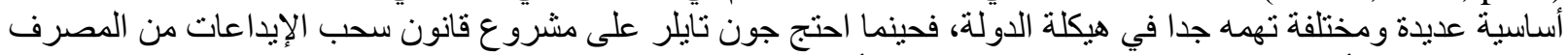

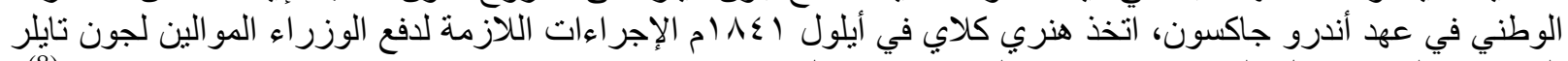

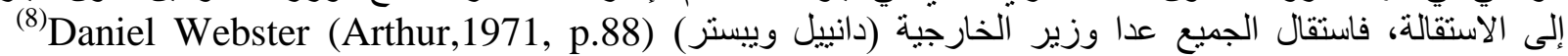

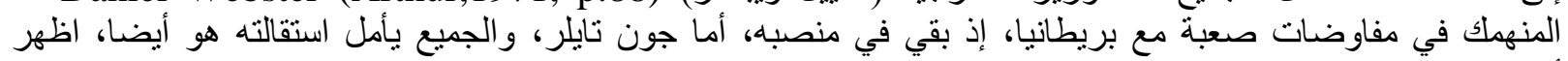

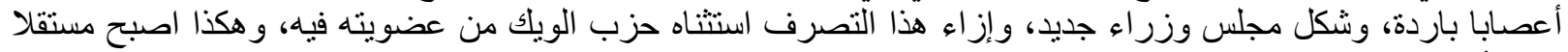

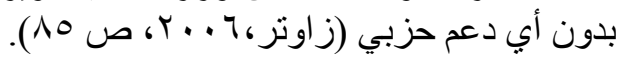

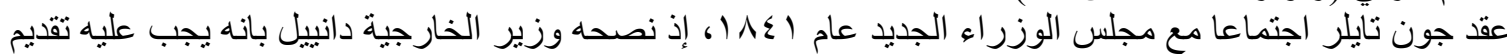

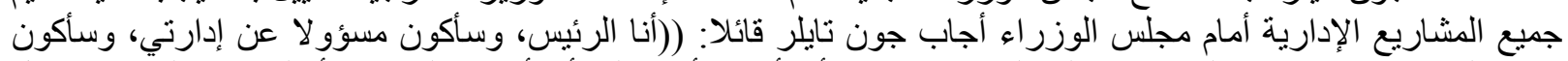

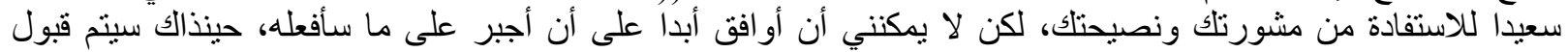

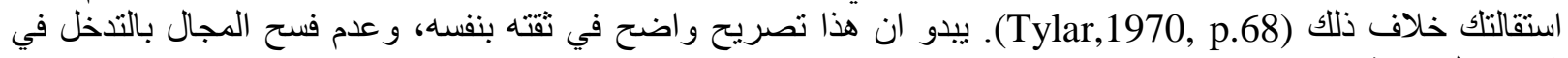
شؤونه السياسية.

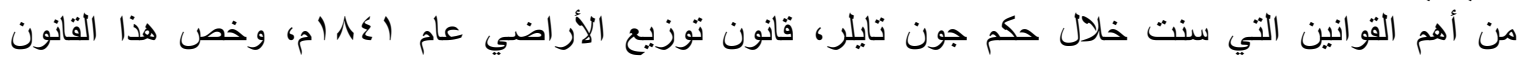

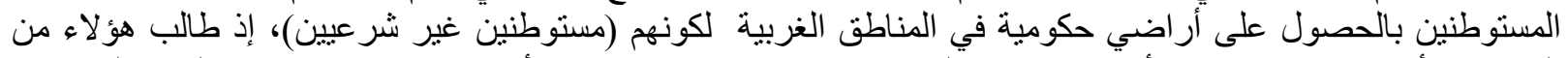

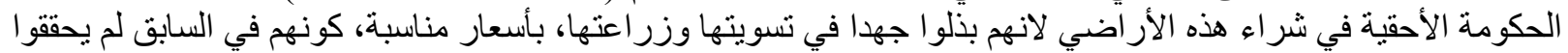

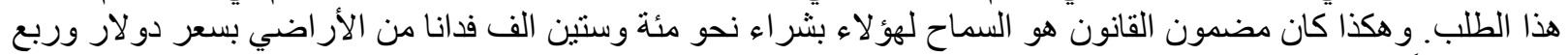

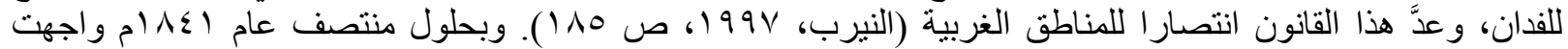

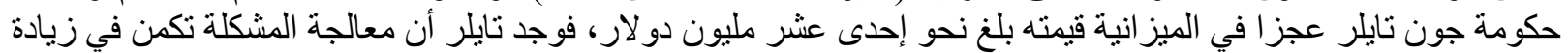

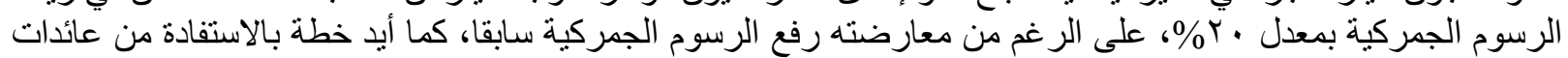

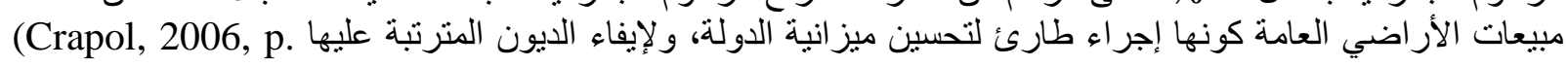

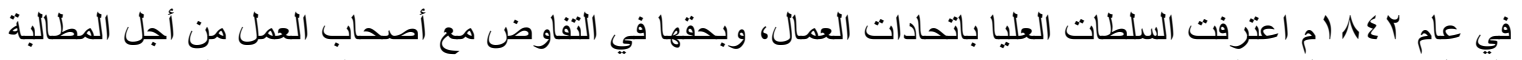

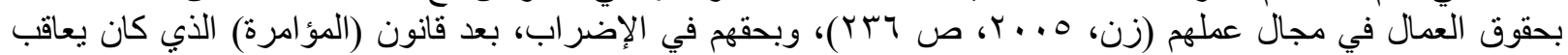

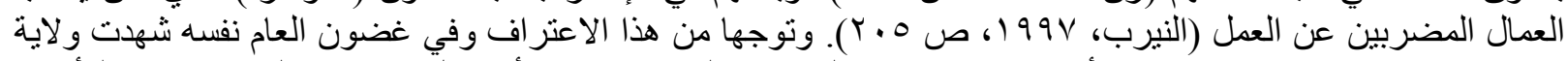

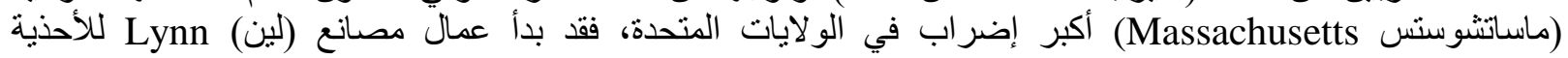


بالإضر اب، إذ كان أصحاب هذه المصانع أول من استخدم ماكينات خياطة الأحذية كي تحل محل العمال (كلود، 919 (، ص

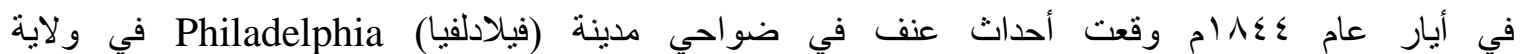

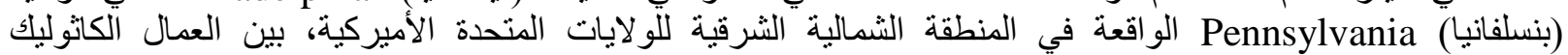

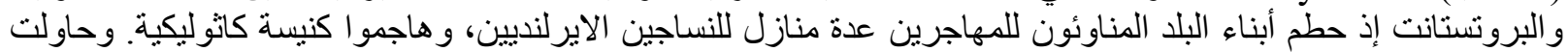

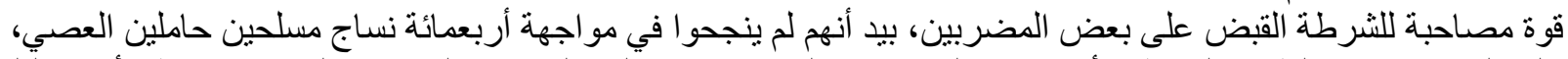

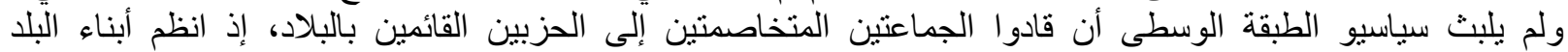

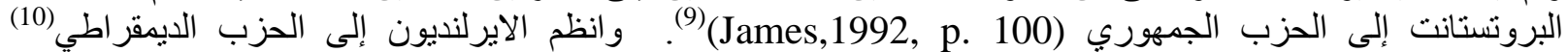

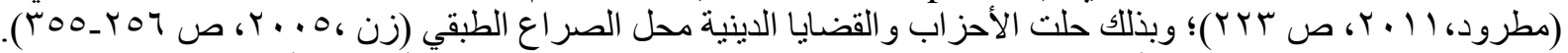

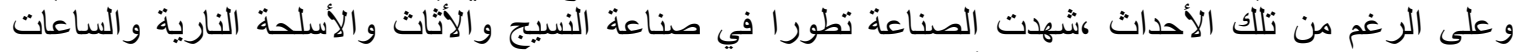

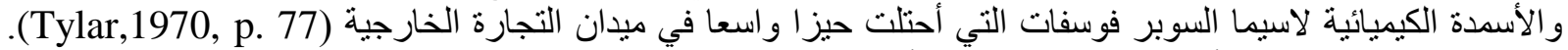

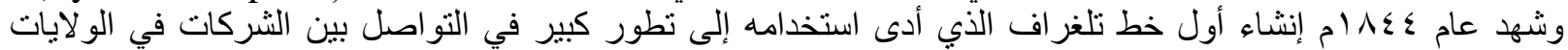

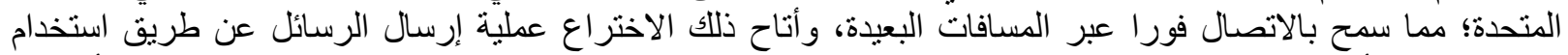

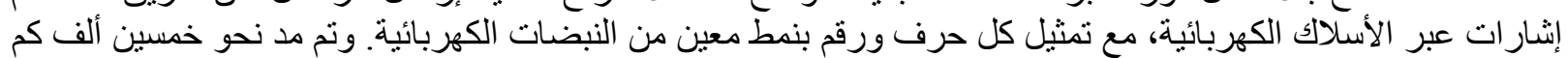

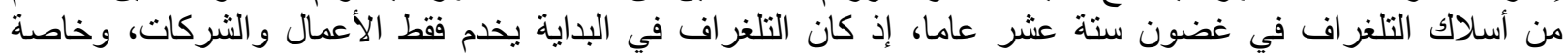

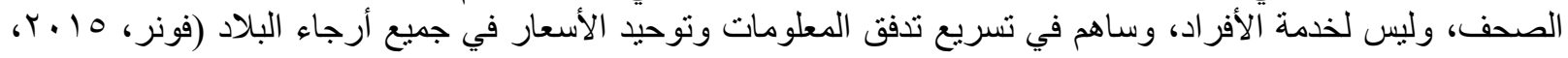

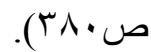

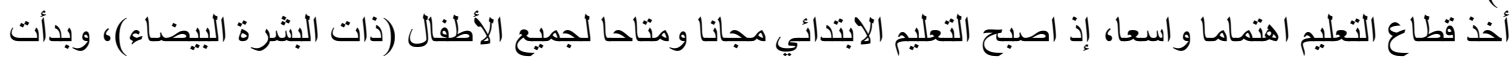

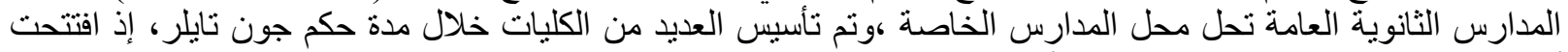

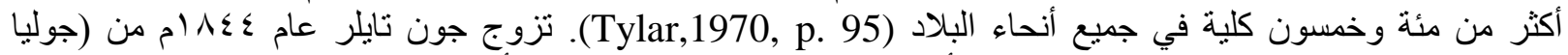

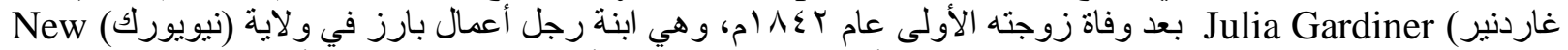

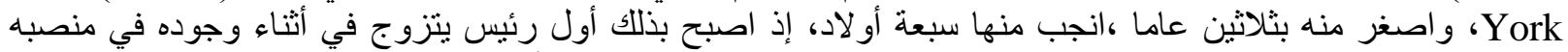

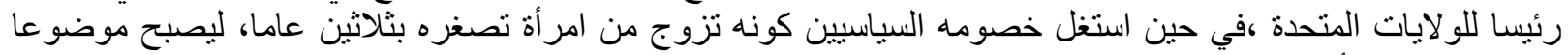

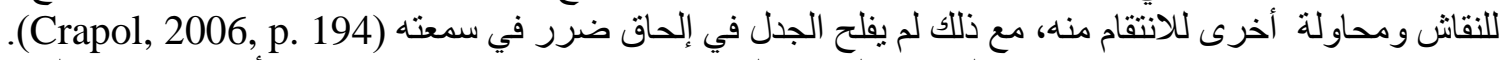

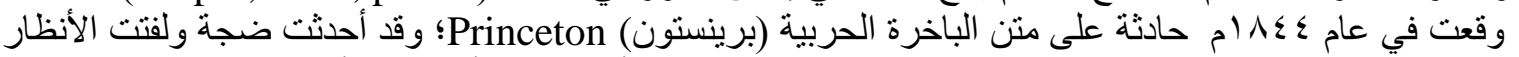

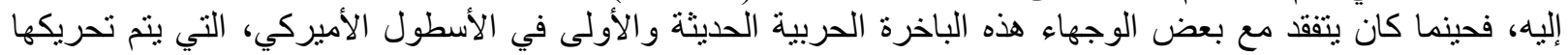

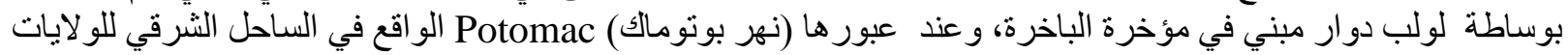

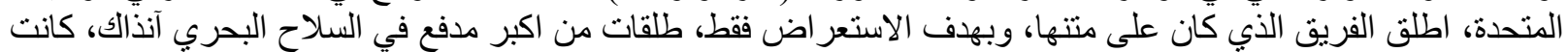

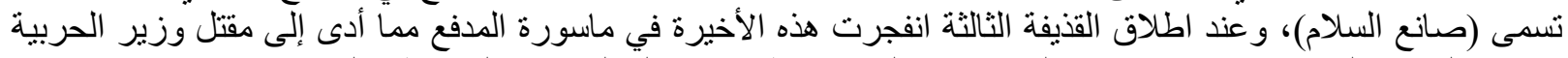

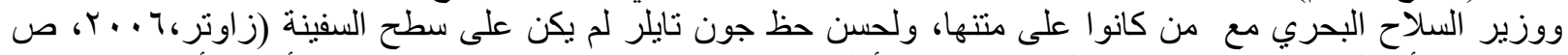

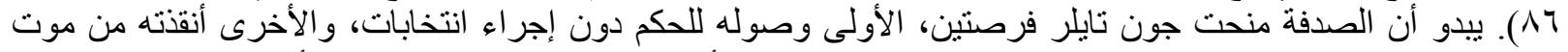

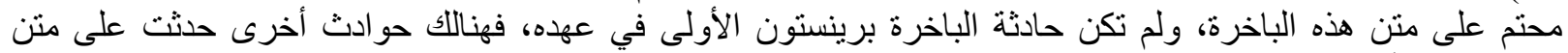

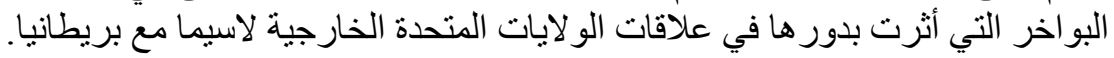

ثالثا: المبحث الثالث بـ السياسة المبثة الخارجية الأميركية خلافل حكم تايلر

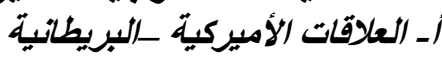

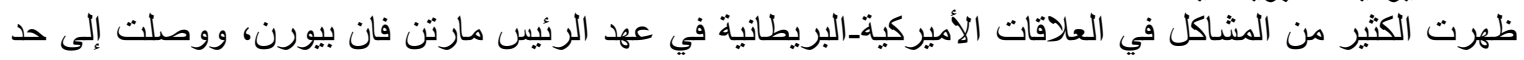

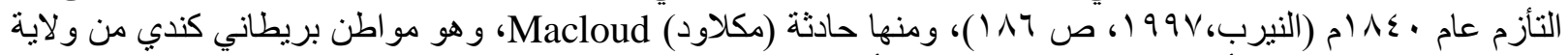

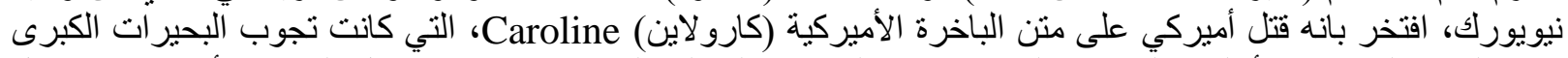

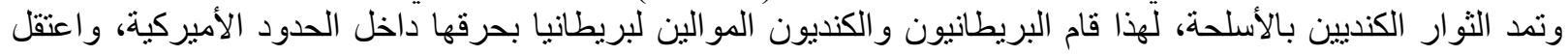

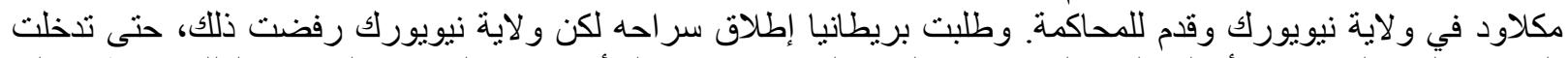

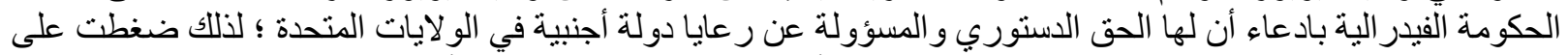

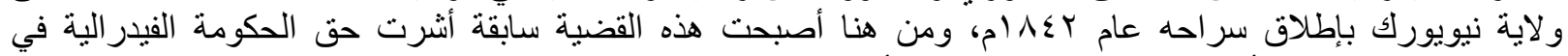

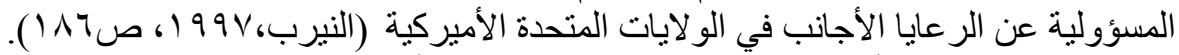

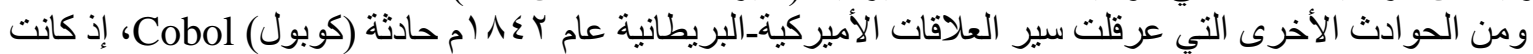

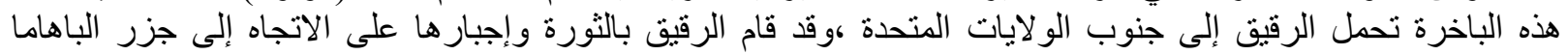

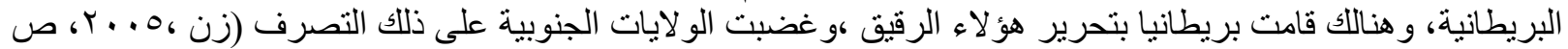




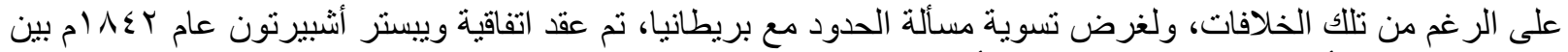

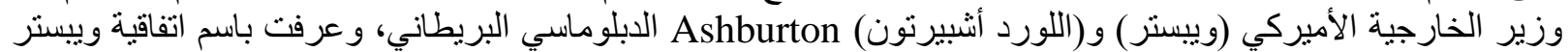

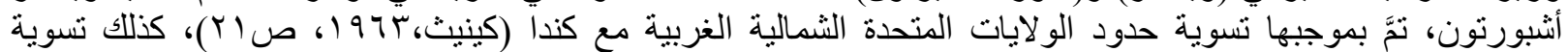

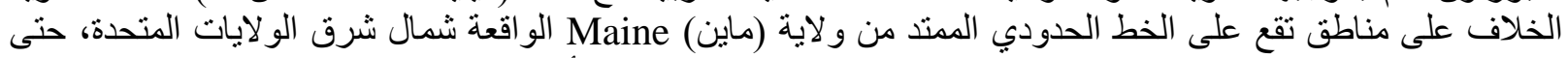

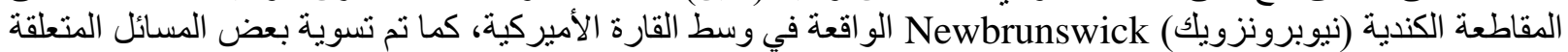

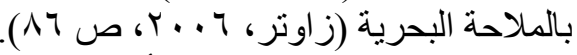

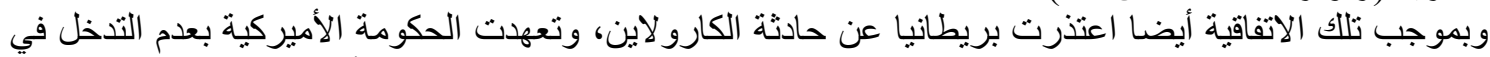

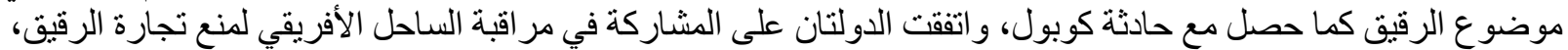

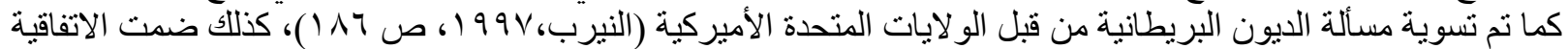

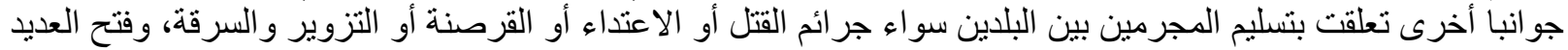
كن الممرات المائية بما في ذللك (نهر سانت جونز) river Sant Johns الو اقع في ولاية (فلوريدا) للملاحة الحرة من قبل المبل

كلا الطرفين (Berkely,1967, p. 199).

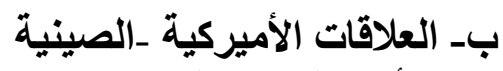

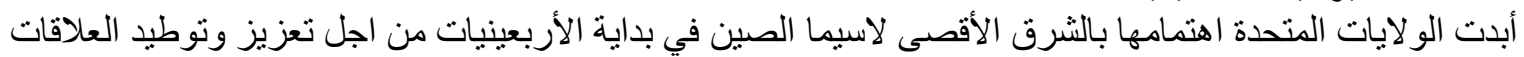

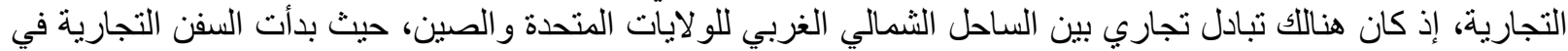

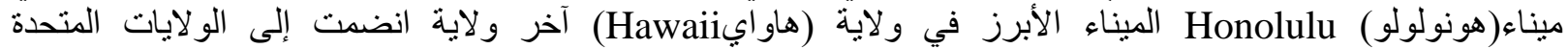

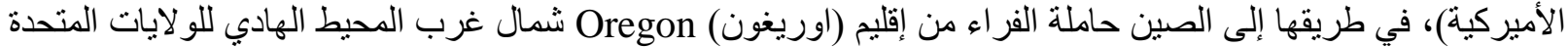

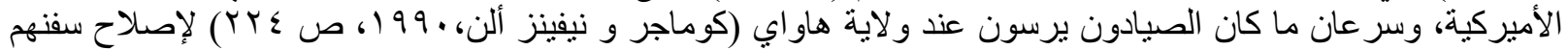
و التزود بالمؤن، وبدأت هونولولو نعج بالئ بالسفن التجارية من مدن سالم (Salem) وبوسطن (Bostin) في و لاية ماساتشوستس

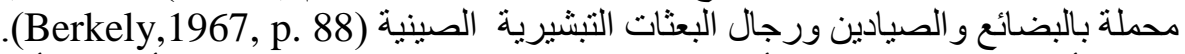

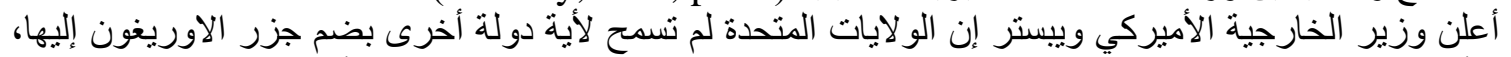

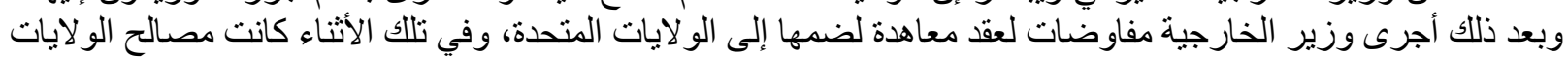

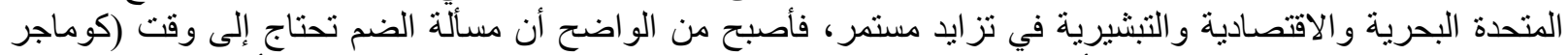

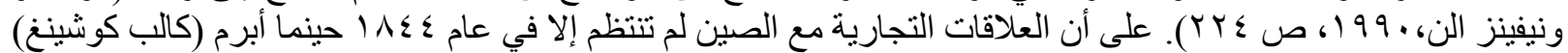
الوزير المفوض الأميركي للمدة (r Caleb Cushing

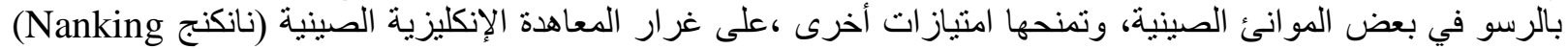

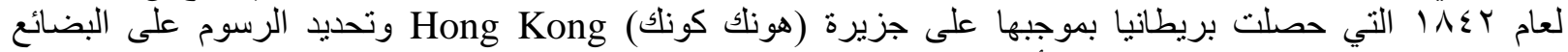

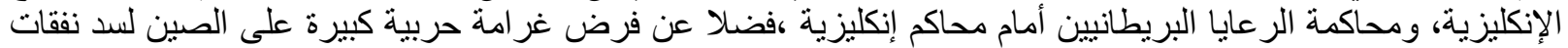

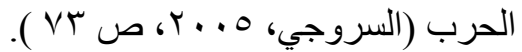

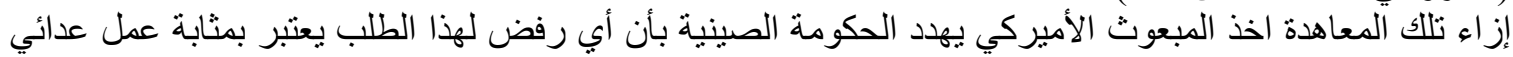

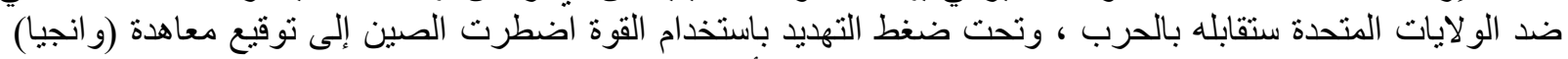

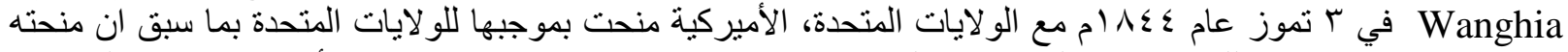

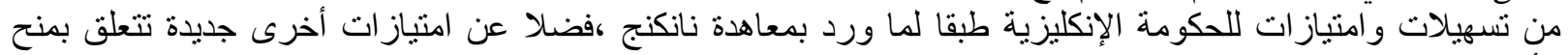

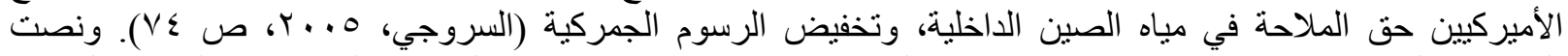

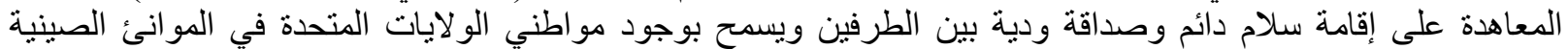

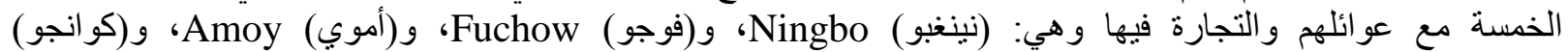

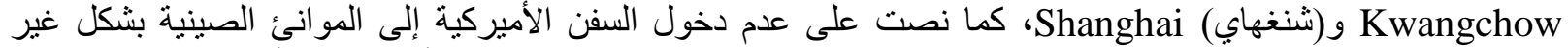

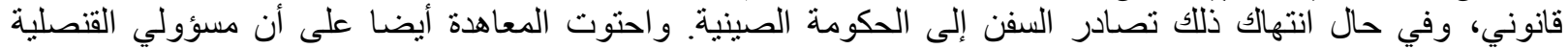

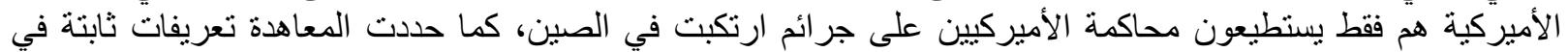

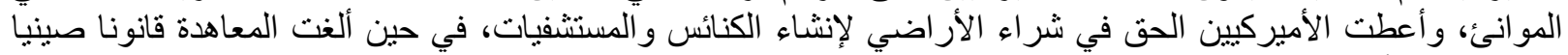

يحظر على الأجانب تعلم اللغة الصينية (Berkely, 1967, p. 251)

ج- ضم تكساس إلى الولايات المتحدة

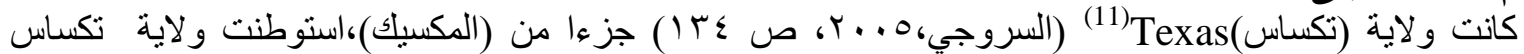

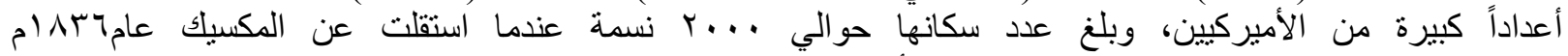

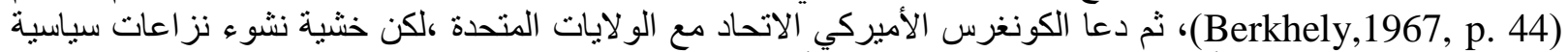

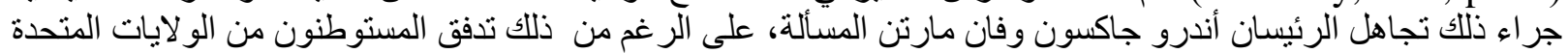


إلى و لاية تكساس، وكان من بينهم العديد من ملاك الرقيق الذين استولوا على الأر اضي الخصبة لزر اعة القطن حتى بلغ عدد

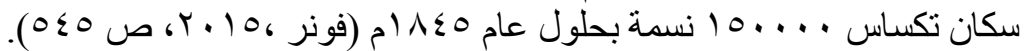

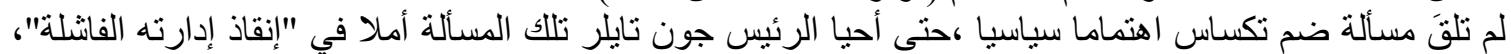

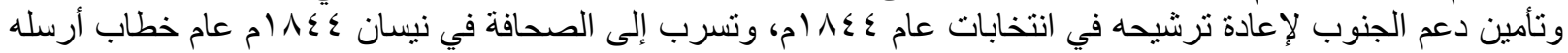

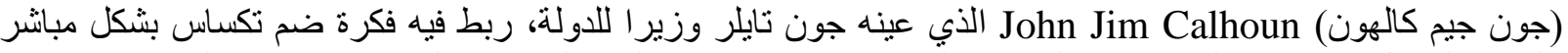

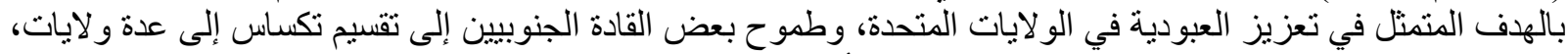

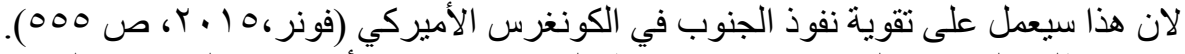

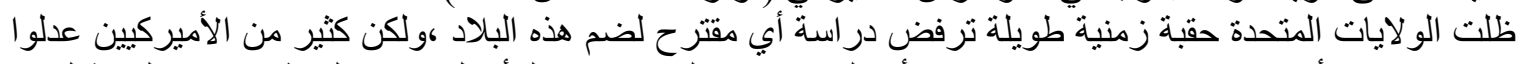

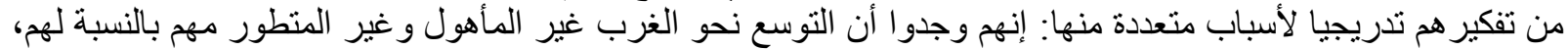

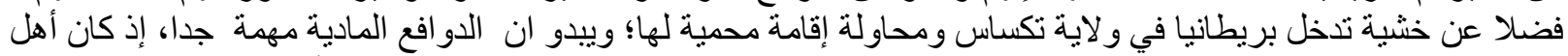

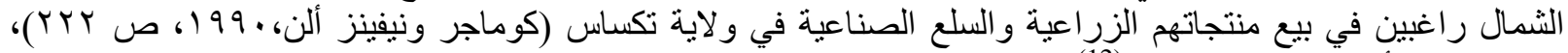

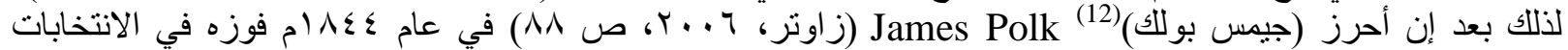

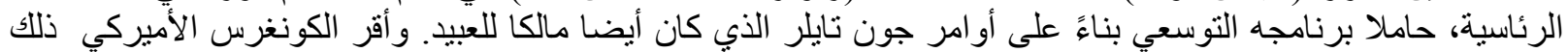

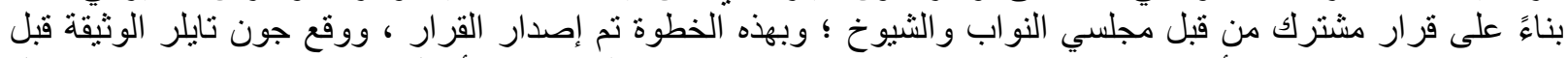

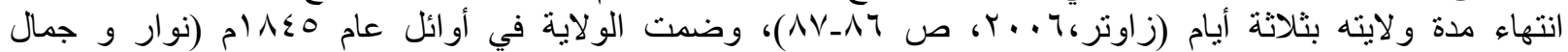

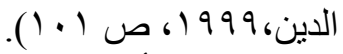

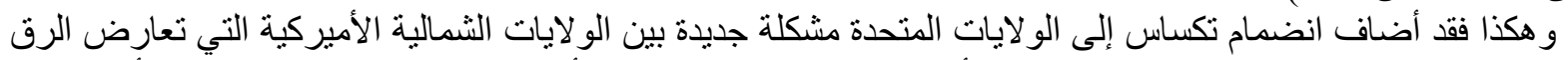

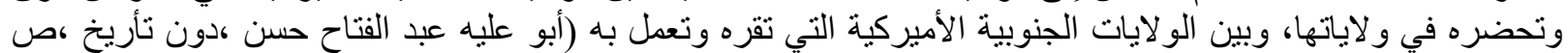

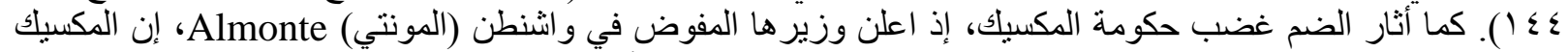

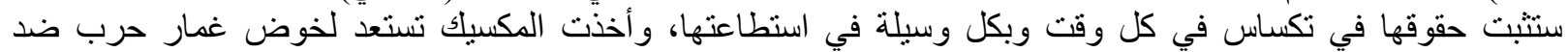

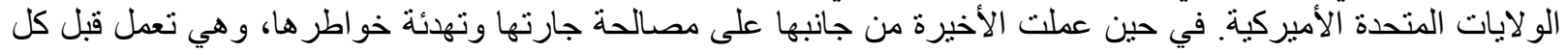

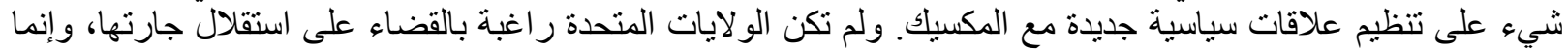

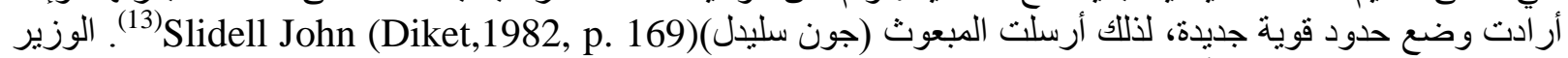

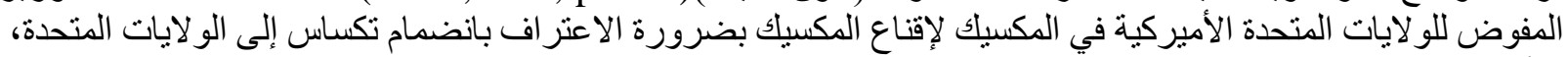

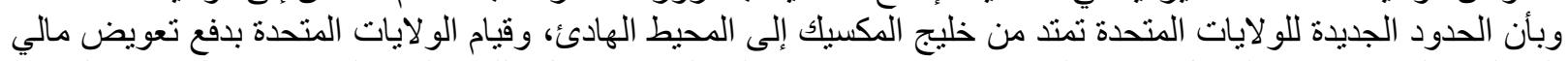

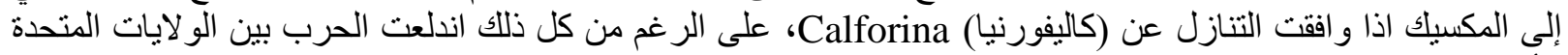

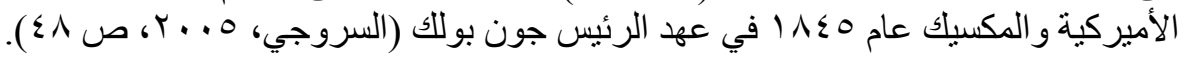

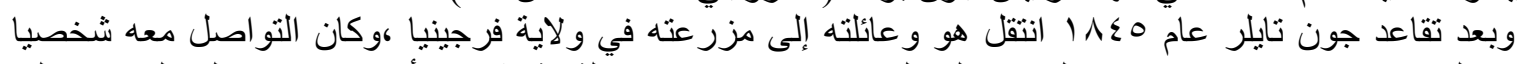

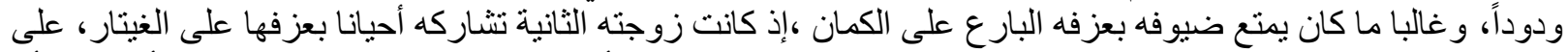

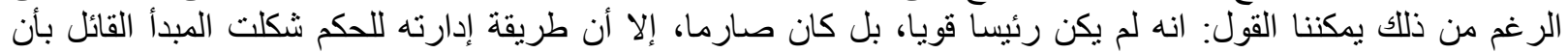

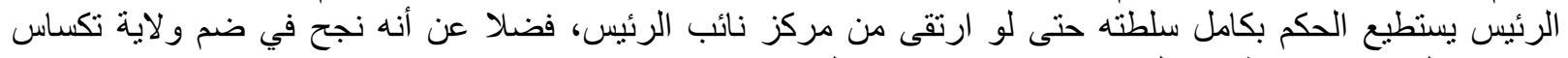

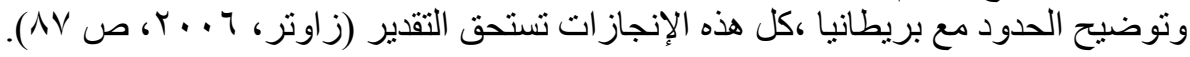

رابعا: الخاتمة ونبة

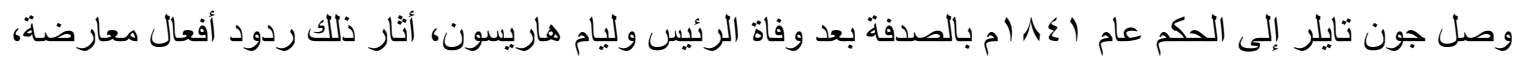

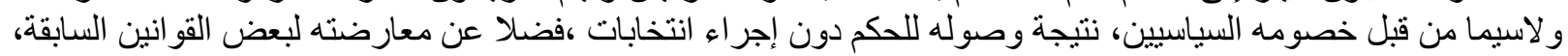

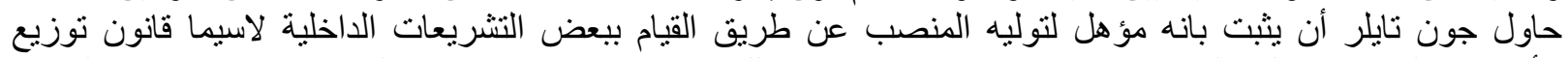

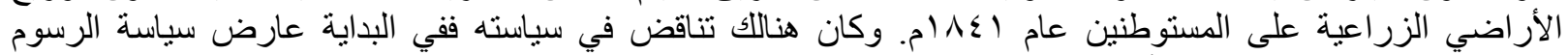

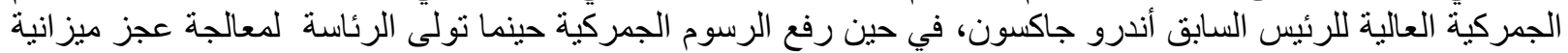

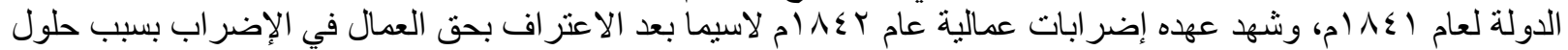

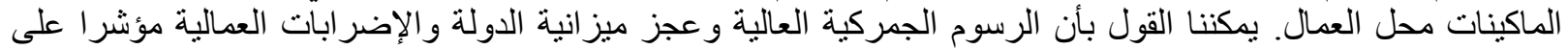

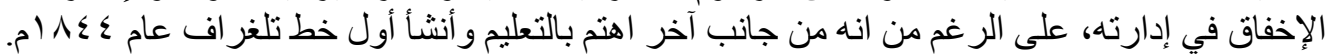

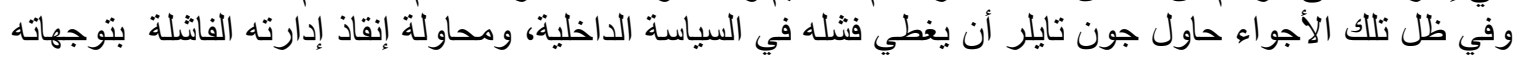

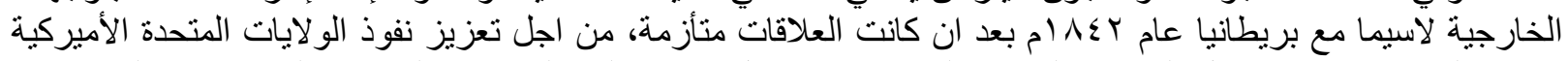

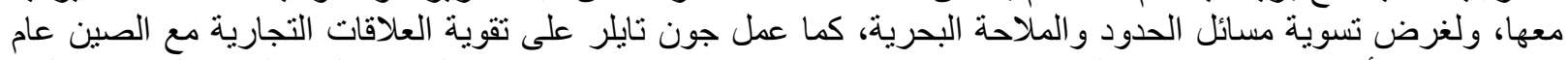

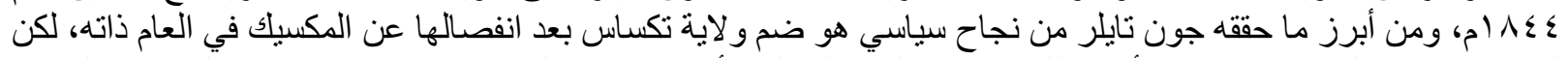

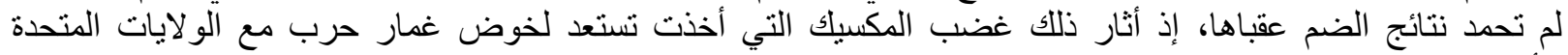
الأميركية في عام 


\section{الكهوامش}

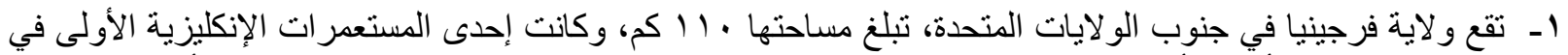

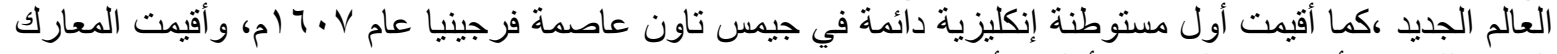

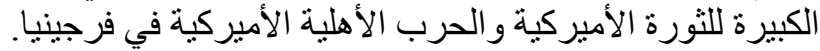

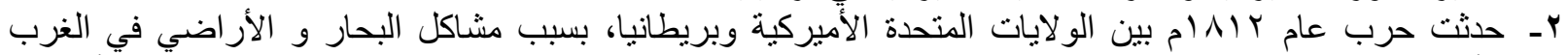

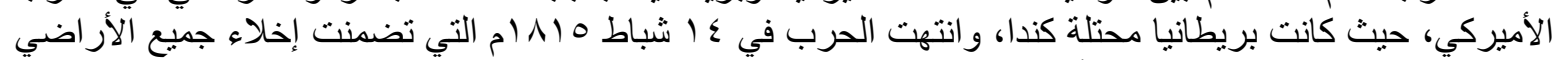

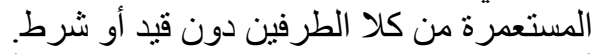

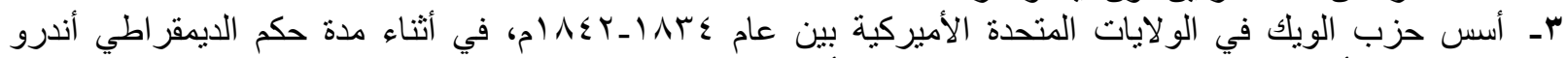

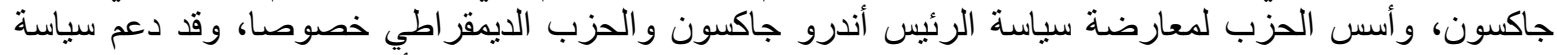

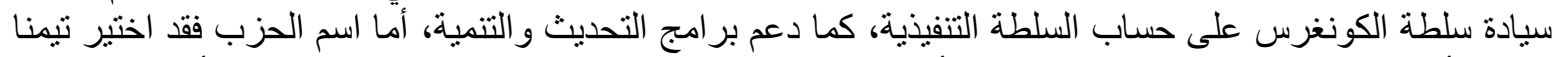

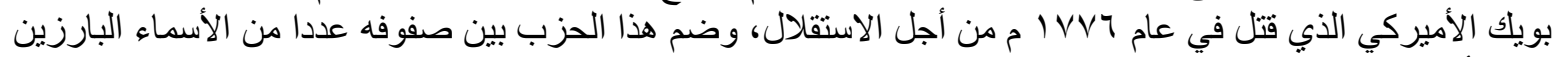

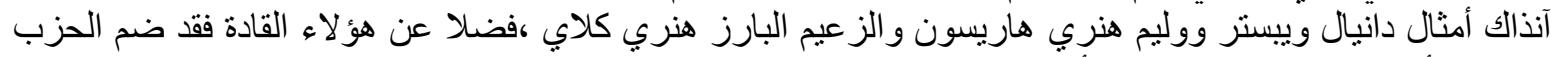

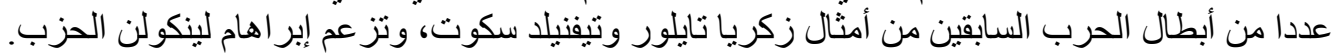

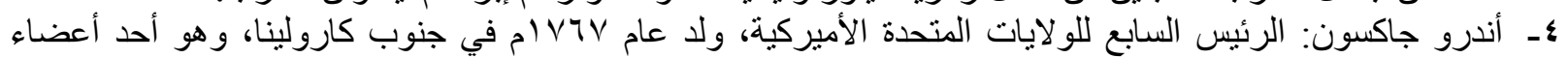

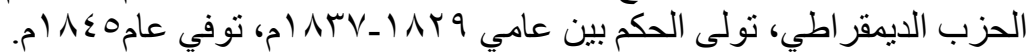

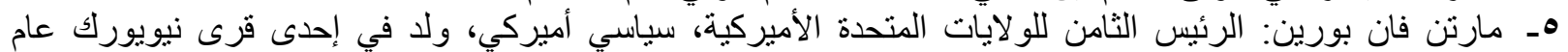

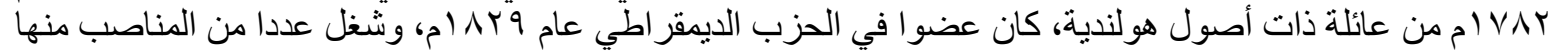

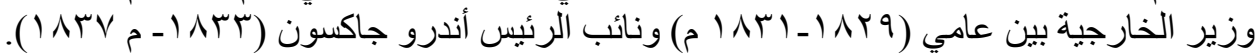

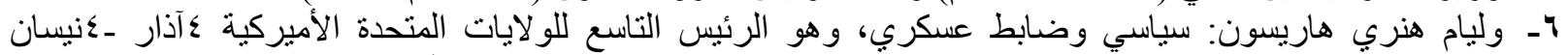

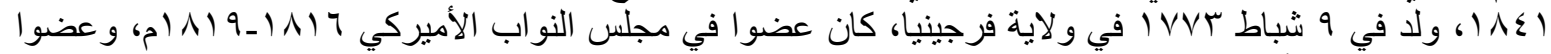

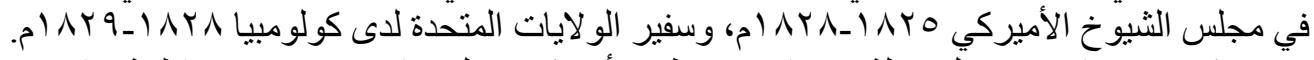

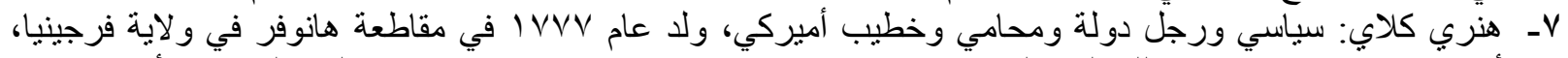

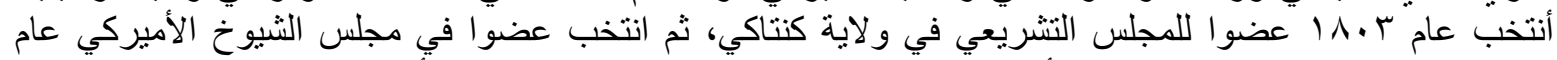

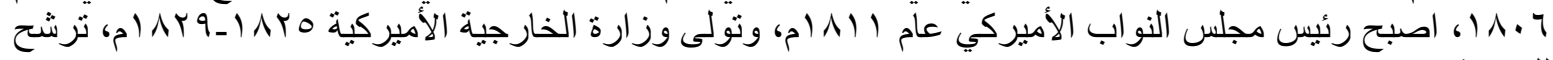

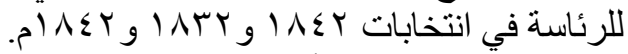

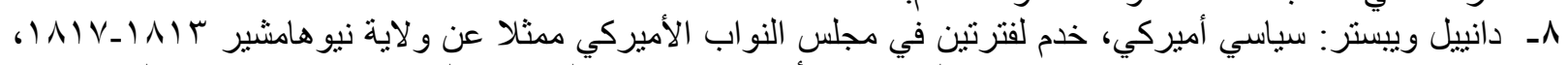

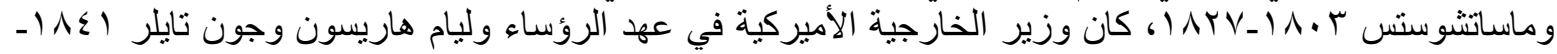

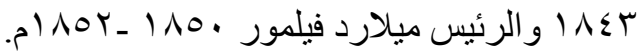

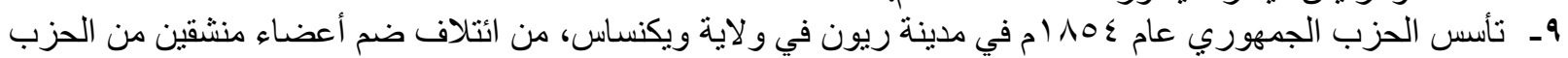

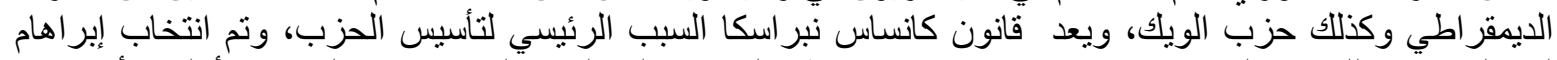

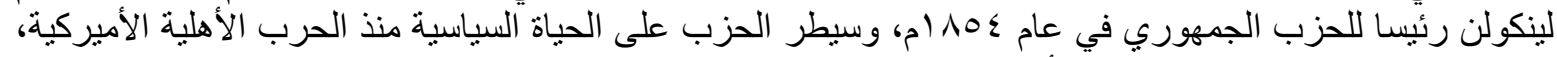

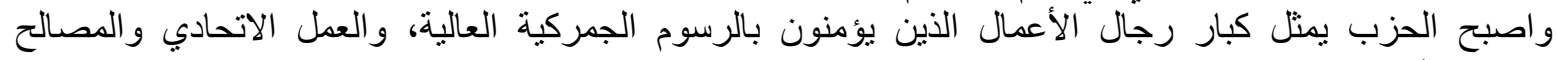
الاقتصادية.

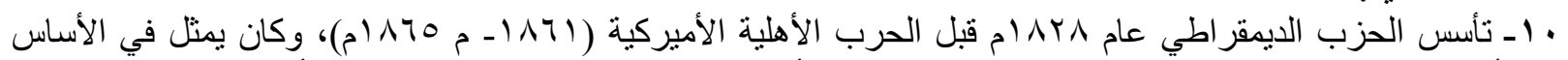

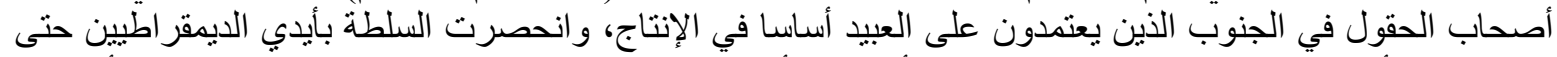

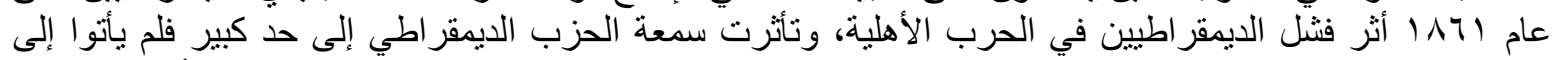

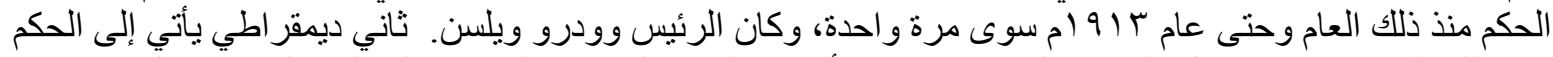

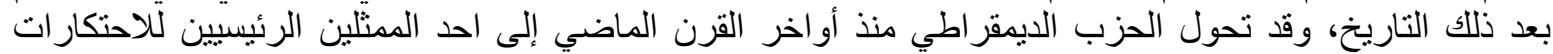

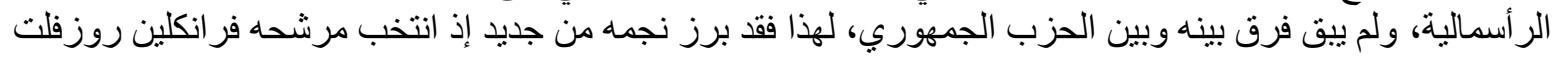

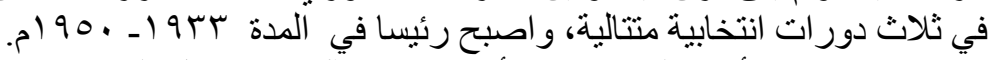

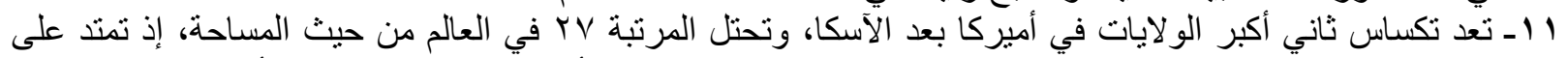

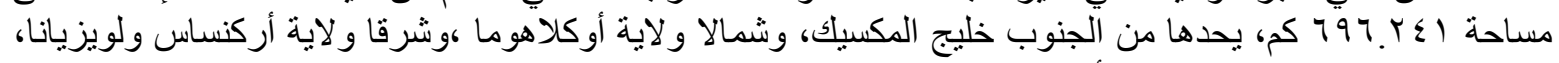

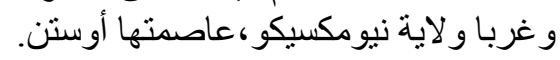

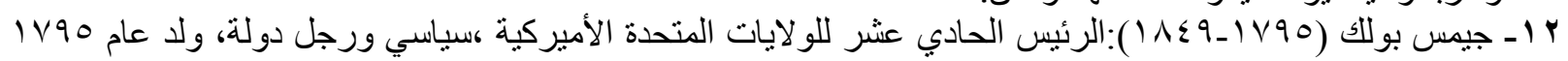

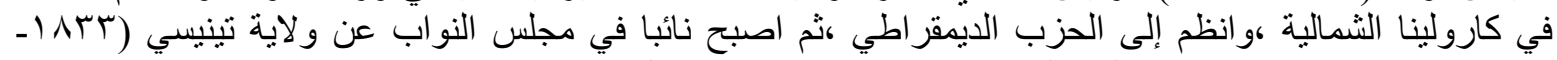

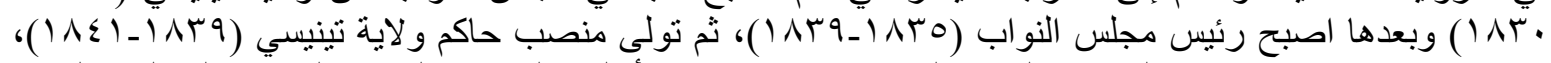

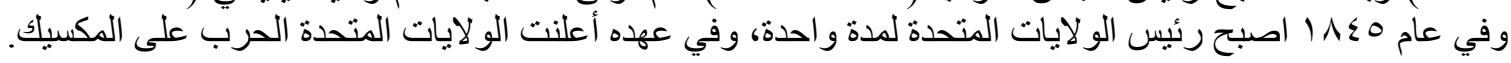




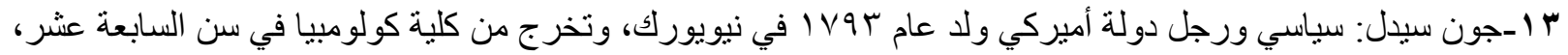

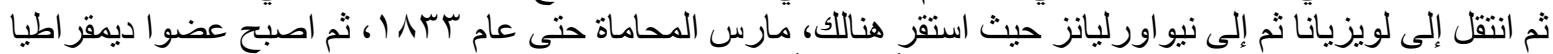

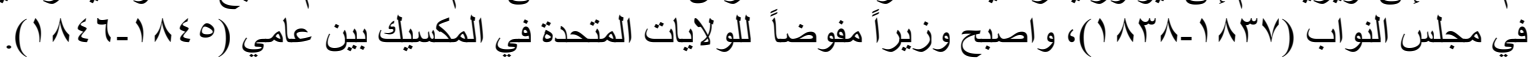

\section{المصادر}

أبو علية، عبد الفتاح حسن. (د.ت). تأريخ الأمريكيتين و التكوين السياسي للو لايات المتحدة الأمريكية. السعودية: دار المئية المريخ.

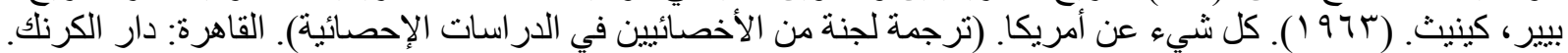

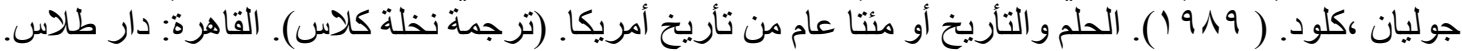

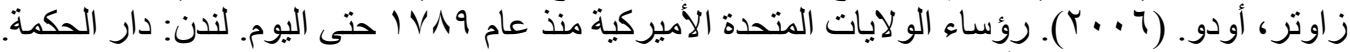

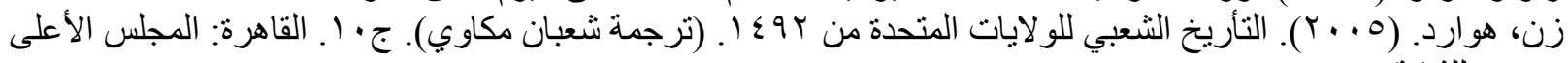
للثقافة.

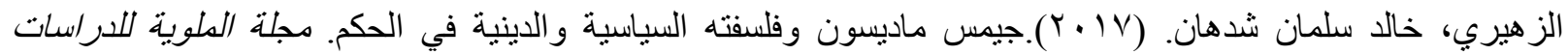

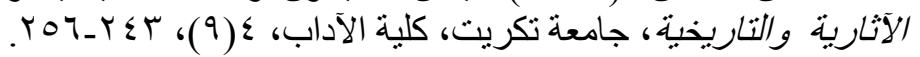

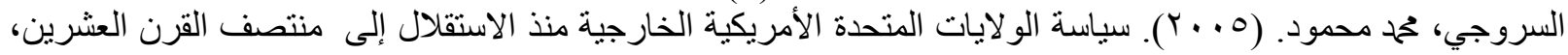

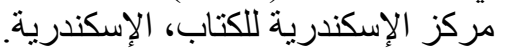

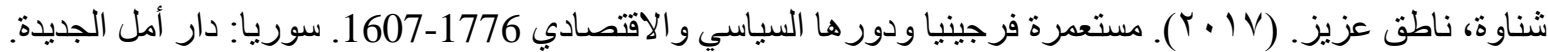

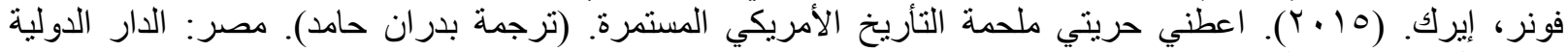
لماستثمار ات الثقافية.

كو ماجر، هنري سنيل و ألن، نيفينز. ( •99 (19). موجز تأريخ الولايات المتحدة. (ترجمة بدر الدين خليل). القاهرة: الدار الدولية لكر، لإستشار ات الثقافية.

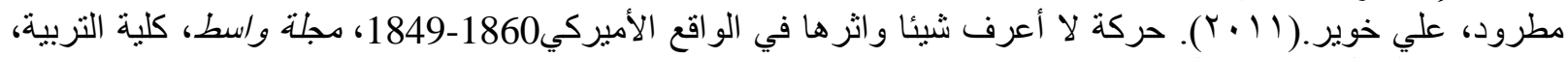

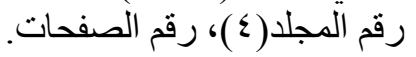

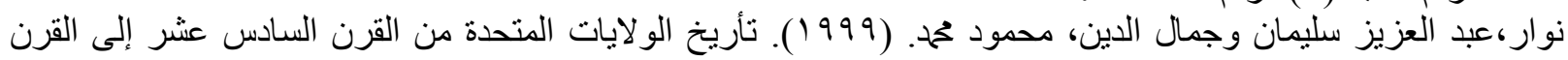
العشرين. بيروت: دار الفكر العربي.

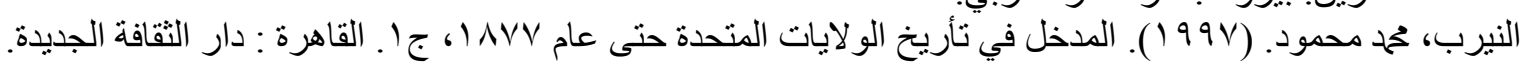




\section{Foresign References}

Arther, M. (1971). History of America presidential. New York. Random House.

Bourne, Kenneth. (1967). Britain and the balance of power in North America 1815-1908. Cliforina: University of Cliforina Press. (Translated by Nakhla Class). Damascus: Damascus publishing center.

Cole, D. (1984). Martin Van Buren and the American political system. New York: Princeton University Press.

Crapol, E. (2006). Jhon Tyler the accidental president. New York: University of North Crolina Press.

Diket, A. (1982). Senator John Slidell and the community herepresented in Washington 18531861 MA. Washinghton: Houghton Mifflin Company.

Eatoa, C. (1957). Henry Clay and the Art of American polities. Boston: Aspen Publishers.

Eaton. C. (1957). History Clay and the art of America politics. Boston: Oxford University Press.

Holt, M. (1992). Political Parties and America political development from age of Jackson to age of Lincoln. New york: DC:CQ Press.

James, R. (1992). The life of the parties' history of American political parties. Washington: publisher.

Monro. D. (2003). The republican vision of John Tyler Texas. Texas: A\&M University Press.

Peterson. N. (1989). The presidencies of William Harrison and Jhon Tyler. New York: University Press of Kansasm.

Sallivan.G. (1977). President abook of U.S president. Washington: TN:Clenmary.

Tyler, L. (1970). The time and times of the Tyler 1881-1860. NewYork: Richard, Va., Whittet \& Shepperson.

William, M. (1914). Party Government in the United States of American. New York: Random House.

\section{References}

Abu Alia, A. (n.d.). History of the Americas and the political composition of the United States of America. Saudi Arabia: Dar Al-marikh.

Al- Nairb, M. (1997).The entry into the history of the United State until the year 1877. Part (1). Cairo: Dar Al-Thaqfa New.

Al-Seruge, M. (2005).U.S foreign policy from independence to the mid-twentieth century. Alexandria: Alexandira Center for Books.

Al-Zuhairi, K. (2017). James Madison and his political and religious philosophy in government. Al Malweah Journal for Archaeological and Historical studies, Tikrit University College of literature, 4(9), 243-256.

Arther, M. (1971). History of American presidential. New York: Musuem of the city.

Bear, K. (1963). Every thing about America, translation of a committee of specialists in statistical studies. Cairo: Dar Alkamak.

Claude, J. (1978). The dream and the the history or two hundred years of America History (Translated by Nakhla Class). Damascus: Tlass House.

Cole, D. (1984). Martin Van Buren and the American political system. New York: Princeton University Press.

Commger, H. \& Allan, N. (1990). A brief History of the United States. (Translated by Mohammed Badreldin Khalil). Cairo: Al-Dar AL-dewelia for education.

Crapol, E. (2006). Jhon Tyler the Accidental president. Carolina: University of North Carolina Press. 
Eatoa, C. (1957). Henry Clay and Art of American Polities. Boston. Kentucky Historical Society, 73(3), 241-262.

Fonner, E. (n.d.). Give me my freedom, the epic of America history. (Translated by Badran Hamid). Cairo: Simon Publication.

James, R. (1992).The life of the Parties History of American Political Parties.Toronto: Philosophy Documentation Center.

Matrud, A. (2008). The movement does not know any thing and its effect in fact America 1849-1860. Journal College of Education, University of Wasit, (4), 8071-1728-6.

Michael, H. (1992). Political parties and American political development from age of Jackson to age of Lincoln. Washington: Stae University Press.

Monroe, Dan. (2003). The Republican vision of Jhon Tyler Texas. Texas: A\&M University Press.

Nawar, A. \& Jamal al-Din, M. (1999). History of the United States from the $16^{\text {th }}$ century to the $20^{\text {th }}$ century. Beirut: Dar Al-Fiker Alarabi.

Peterson, N. (1989). The presidencies of William Harrison and Jhon Tyler. University Press of Kansas: Kansas Publishing Center.

Sallivan, N. \& Hajeski, J. (1977). President: A book of U.S presidents. Whasughton: Whasughton Press.

Shenawa, N. (2017).Virginia Colony and its political and economic role 1607-1776. Syria: Dar-Alamal.

William, M. (1914). Party Government in the United States of American. New York: Oxford University Press.

Zauter, O. (2006).Presidents of the United States of A merica from 1789 to today. London: Dar Al-Hikma.

Zin, H. (2005). The popular history of the United State to 1492. (Translated by Shaaban Makaw M). Part One. Cairo: Cairo Publishing House. 